\title{
Co-localizing linguistic and musical syntax with intracranial EEG
}

\author{
Daniela Sammler ${ }^{\mathrm{a}, *}$, Stefan Koelsch ${ }^{\mathrm{a}, \mathrm{b}}$, Tonio Ball ${ }^{\mathrm{c}, \mathrm{d}}$, Armin Brandt ${ }^{\mathrm{c}}$, Maren Grigutsch ${ }^{\mathrm{a}}$, \\ Hans-Jürgen Huppertz e, Thomas R. Knösche a, Jörg Wellmer f,g, Guido Widman ${ }^{\mathrm{f}}$, Christian E. Elger ${ }^{\mathrm{f}}$, \\ Angela D. Friederici ${ }^{a}$, Andreas Schulze-Bonhage ${ }^{c, d}$ \\ a Max Planck Institute for Human Cognitive and Brain Sciences, Stephanstraße 1a, 04103 Leipzig, Germany \\ b Cluster of Excellence "Languages of Emotion", Freie Universität Berlin, Halberschwerdter Allee 45, 14195 Berlin, Germany \\ c Epilepsy Center, University Medical Center Freiburg, Breisacher Straße 64, 79106 Freiburg, Germany \\ d Bernstein Center Freiburg (BCF), University of Freiburg, Hansastraße 9a, 79104 Freiburg, Germany \\ e Swiss Epilepsy Centre, Bleulerstraße 60, 8008 Zurich, Switzerland \\ ${ }^{\mathrm{f}}$ Clinic of Epileptology, University Hospital of Bonn, Sigmund-Freud-Straße 25, 53105 Bonn, Germany \\ ${ }^{g}$ Ruhr-Epileptology, University of Bochum, In der Schornau 23-25, 44892 Bochum, Germany
}

\section{A R T I C L E I N F O}

\section{Article history:}

Accepted 13 September 2012

Available online 20 September 2012

\section{Keywords:}

Language

Music

Syntax

Intracranial EEG

Early Left Anterior Negativity (ELAN)

Early Right Anterior Negativity (ERAN)

\begin{abstract}
A B S T R A C T
Despite general agreement on shared syntactic resources in music and language, the neuroanatomical underpinnings of this overlap remain largely unexplored. While previous studies mainly considered frontal areas as supramodal grammar processors, the domain-general syntactic role of temporal areas has been so far neglected. Here we capitalized on the excellent spatial and temporal resolution of subdural EEG recordings to co-localize low-level syntactic processes in music and language in the temporal lobe in a within-subject design. We used Brain Surface Current Density mapping to localize and compare neural generators of the early negativities evoked by violations of phrase structure grammar in both music and spoken language. The results show that the processing of syntactic violations relies in both domains on bilateral temporofronto-parietal neural networks. We found considerable overlap of these networks in the superior temporal lobe, but also differences in the hemispheric timing and relative weighting of their fronto-temporal constituents. While alluding to the dissimilarity in how shared neural resources may be configured depending on the musical or linguistic nature of the perceived stimulus, the combined data lend support for a co-localization of early musical and linguistic syntax processing in the temporal lobe.
\end{abstract}

(C) 2012 Elsevier Inc. All rights reserved.

\section{Introduction}

Language and music are two primary channels of human auditory communication, and their similarities and differences have long interested scholars (Darwin, 1871/1989; Koelsch, 2012; Patel, 2008; Rousseau, 1781/1998; Wallin et al., 2000). A great deal of work has concentrated on syntax in both domains, i.e. the rules that determine how single words or notes are strung together into sentences or musical pieces in a way that meaning and harmony build up over the course of the sequence. Comparative research of psycholinguists and musicologists has stressed the similar syntactic architecture of language and music, both sharing hierarchical and recursive features hidden behind

Abbreviations: BA, Brodmann area; BSCD, brain surface current density; ECoG, electrocorticography; EEG, electroencephalography; ELAN, early left anterior negativity; ERAN, early right anterior negativity; ERP, event-related potential; fMRI, functional magnetic resonance imaging; IFG, inferior frontal gyrus; IPL, inferior parietal lobe; MEG, magnetoencephalography; MTG, middle temporal gyrus; PCG, postcentral gyrus; PrCG, precentral gyrus; SMG, supramarginal gyrus; STG, superior temporal gyrus; STS, superior temporal sulcus.

* Corresponding author. Fax: +493419940 2260.

E-mail address: sammler@cbs.mpg.de (D. Sammler). a linear surface structure that may be best visualized as syntactic trees (language: Chomsky, 1957, 1995) (music: Katz and Pesetsky, 2011; Lerdahl and Jackendoff, 1983; Rohrmeier, 2011). Based on these formal parallels, neurocognitive theories proposed that language comprehension and music perception should share a set of cognitive operations to segment, parse, and integrate the syntactic structure of speech and music streams, and be grounded in jointly recruited cortical areas (Koelsch, 2011; Patel, 2003).

Much effort has been made to prove the functional overlap of syntactic operations in music and language (for an overview, see Koelsch, 2011) by means of interference paradigms in behavioral (Fedorenko et al., 2009; Slevc et al., 2009) and event-related potential studies (ERP; Koelsch et al., 2005a; Steinbeis and Koelsch, 2008), the demonstration of syntactic enhancement in one domain after training in the other domain (Jentschke and Koelsch, 2009; Jentschke et al., 2005; Marin, 2009), and the occurrence of parallel agrammatic deficits in both language and music (Jentschke et al., 2008; Patel et al., 2008). The neuroanatomical underpinnings of these observed interactions are currently hotly debated. Where would a supramodal "syntax processor" be located in the brain? A majority of researchers assume that the frontal lobe hosts domain-general syntactic resources (Fadiga et al., 2009; 
Fiebach and Schubotz, 2006; Gelfand and Bookheimer, 2003; Koelsch, 2005; Patel, 2003; Tettamanti and Weniger, 2006) though to date this is not unequivocally proven (Fedorenko et al., 2011; Rogalsky et al., 2011). Alternatively, the possibility of overlapping syntactic processes in temporal brain areas has been mostly neglected, although these regions are frequently reported as part of the syntax processing network in language (Kaan and Swaab, 2002) and music (Koelsch et al., 2002). Here we report for the first time on the neuroanatomical co-localization of early musical and linguistic syntax processing in the temporal lobe.

For a long time, syntax processing has been regarded as one cardinal function of the left inferior frontal gyrus (IFG; Bookheimer, 2002; Friederici, 2002; Grodzinsky and Santi, 2008; Moro et al., 2001; Musso et al., 2003; Sahin et al., 2009). Its presumed role in integrating single linguistic items into larger, hierarchical structures (Friederici, 2002; Hagoort, 2005; Shalom and Poeppel, 2008; Ullman, 2001) and the predictive power of these structures to generate expectancies of forthcoming events are exactly the core processes that are assumed to be shared by language and music (Brown et al., 2006; Koelsch, 2009; Patel, 2003). However, the circuitry of syntactic comprehension clearly involves a broader network beyond the frontal lobe, including anterior, middle, and posterior temporal areas as demonstrated by numerous language neuroimaging studies probing syntax processing (Friederici et al., 2003, 2010; Humphries et al., 2005, 2006; Kaan and Swaab, 2002; Noppeney and Price, 2004; Spitsyna et al., 2006; Tyler et al., 2011; Vandenberghe et al., 2002). One specific role of the temporal lobe in language is the retrieval of word-level syntactic information such as word category and its matching with contextually predicted phrasal constituents (Friederici, 2002; Hagoort, 2009; Pulvermüller and Shtyrov, 2006; Snijders et al., 2009). Notably, these low-level procedures clearly differ from the higher-order combinatorial function of the frontal lobe (Friederici, 2002; Shalom and Poeppel, 2008), although successful syntactic parsing requires the mutual information exchange between temporal and frontal areas via white matter fiber tracts (Friederici, 2009; Tyler and Marslen-Wilson, 2008).

If language and music syntax processing are really similar (Koelsch, 2005, 2011; Patel, 2003, 2008), neural resource overlap should not be restricted to higher-order computations in the frontal lobe, but is likely to concern low-level syntactic retrieval and matching processes in the temporal lobe as well. Indirect support for this idea comes from the similarity of brain potentials evoked by syntactic violations in language and music ERP studies. In language, the presentation of an unexpected syntactic word category elicits an Early Left Anterior Negativity (ELAN; Friederici et al., 1993; Hahne and Friederici, 1999; Lau et al., 2006; Neville et al., 1991). The ELAN peaks between 100 and 200 ms after presentation of the syntactic violation, and may be interpreted as an "error signal" evoked whenever the incoming word does not match the expected category, hindering initial phrase-structure building. Most importantly, generators of the ELAN have been localized in the anterior superior temporal gyrus (STG) with weaker inferior frontal lobe contribution (Friederici et al., 2000; Groß et al., 1998; Herrmann et al., 2011b). In music, the presentation of a harmonically unexpected chord at the end of a sequence of harmonies evokes an Early Right Anterior Negativity (ERAN; Koelsch, 2009; Koelsch et al., 2000) that shows correspondence to the ELAN with regard to functional characteristics, latency, polarity and assumed neural generators. Note that although the ELAN shows left-, and the ERAN right-hemispheric weighting, both components have generators in both hemispheres (ELAN: Friederici et al., 2000; Herrmann et al., 2011b; Knösche et al., 1999; ERAN: Maess et al., 2001). Correspondingly, bilateral temporal and frontal activations (with different hemispheric weighting) were frequently observed in fMRI studies during the processing of linguistic (Kaan and Swaab, 2002; Vigneau et al., 2006, 2011) and musical syntax (Abrams et al., 2011; Koelsch et al., 2002; Koelsch et al., 2005b; Krumhansl, 2004; Minati et al., 2008; Tillmann et al., 2006). Consequently, a number of studies, including the present study, use the labels ELAN and ERAN for their established functional significance, rather than to indicate a significant lateralization (e.g., Eckstein and Friederici, 2006; Koelsch, 2009). Overall, the similarities of ELAN and ERAN have frequently been taken as indices for a noticeable overlap of (early) syntactic mechanisms in language and music, located in the temporal and frontal lobes (Koelsch, 2005, 2011).

\section{The present study}

This body of work qualifies the superior temporal and inferior frontal lobes as likely shared regions in musical and linguistic syntax processing. However, the ultimate proof of this assumption requires (a) a within-subject (as opposed to between-subjects) comparison of supposedly analogous syntactic operations in music and language, (b) a demonstration of overlap at single-subject level, because averaging across individually variable anatomy blurs brain activations and can create an artificial overlap of closely neighboring, but non-overlapping, functions (Cohen et al., 2004; Fedorenko et al., 2012; Korzyukov et al., 2007; Ojemann, 1979), (c) a high spatial resolution, as well as (d) a high temporal resolution to not confound early and late syntactic processes. So far, no study has ever fulfilled these requirements, and the broadly accepted assumption of neuroanatomically overlapping syntactic functions is mainly based on between-subjects comparisons of group average data. While these limitations can be easily circumvented in future study designs (Abrams et al., 2011), demands (c) and (d) are hard to meet with conventional EEG/MEG and fMRI methods because they do not provide sufficient spatial and temporal resolution at the same time.

The present study used intracranial EEG recordings to assess the assumed co-localization of low-level syntactic processes in the temporal lobe. The major benefits of intracranial recordings are their excellent temporal resolution along with a spatial resolution that largely excels the one achieved with scalp EEG and shows superior robustness against recording artifacts (Ball et al., 2009; Bullock et al., 1995; Lachaux et al., 2003; Menon et al., 1996; Zaveri et al., 2009). Thus intracranial recordings provide optimal signal quality for the localization of transient electrophysiological effects like the ELAN and ERAN. We compared linguistic and musical syntax processing in five patients with subdural electrodes implanted in the left or right perisylvian region for presurgical evaluation of temporal lobe epilepsy. In each patient, we applied both a sentence comprehension (Friederici et al., 1993; Hahne and Friederici, 1999) and a chord sequence paradigm (Koelsch, 2009) containing syntactic violations known to evoke an ELAN or ERAN in scalp recordings, i.e. triggering supposedly similar early syntactic processes in both domains. The electrocortical equivalents of the ELAN and ERAN were identified individually and subjected to Brain Surface Current Density (BSCD) mapping in order to reconstruct and compare their neural generators. If low-level syntactic processes in language and music as reflected in the ELAN and ERAN share resources in the temporal lobe, this should be seen in a spatial overlap of their neural generators in respective areas within subjects.

\section{Material and methods}

\section{Participants}

Data were obtained from 5 adult patients (Table 1) undergoing presurgical evaluation of pharmacoresistant epilepsies by means of subdural electrodes. In three patients, electrodes covered left, in two patients right perisylvian brain areas (for electrode positions, see Supplementary Fig. S1). The mean duration of epilepsy was 18.6 years (for medical details, see Table 2). All patients were native speakers of German, right-handed, and had left-hemispheric language dominance. None of them was a professional musician. 
Table 1

Personal data of the patients.

\begin{tabular}{lllllll}
\hline Patient & Age & Gender & $\begin{array}{l}\text { Handed-ness } \\
\text { (LQ) }\end{array}$ & $\begin{array}{l}\text { Language } \\
\text { Dominance }\end{array}$ & $\begin{array}{l}\text { School } \\
\text { Education }\end{array}$ & $\begin{array}{l}\text { Musical } \\
\text { Training }\end{array}$ \\
\hline P1 & 29 & M & R (83) & left (fMRI) & 12 years & 2 years \\
P2 & 18 & M & R (75) & left (fMRI/e-stim.) & 12 years & 4 years \\
P3 & 28 & F & R (80) & left (fMRI/e-stim.) & 9 years & 2 years \\
P4 & 28 & F & R (82) & left (fMRI) & 12 years & 4 years \\
P5 & 53 & M & R (100) & left (fMRI) & 10 years & 0 years \\
\hline
\end{tabular}

Gender: $\mathrm{F}=$ female, $\mathrm{M}=$ male. Handedness is indicated according to the Edinburgh Handedness Inventory (Oldfield, 1971): LQ= laterality quotient, $\mathrm{R}=$ right handed. Language dominance was assessed as part of the patients' clinical evaluation using standard fMRI protocols or electrical stimulation (e-stim.). Musical training indicates the accumulated years of playing an instrument.

\section{Stimulus material}

All patients participated in a language and a music experiment. In the language experiment, patients listened to short sentences that were either syntactically correct or incorrect (mean duration: $1738 \mathrm{~ms}$, range: 1268-2670 ms; Hahne and Friederici, 1999; see left panel of Fig. 1). Correct sentences consisted of a noun phrase [Np], an auxiliary [Aux], and a past participle [Pp] (e.g., Das Geheimnis wurde geflüstert. The secret was whispered.). Syntactically incorrect counterparts of these sentences contained an additional preposition-determiner combination [P] before the past participle (e.g., * Der Plan wurde im geflüstert. - The plan was in-the whispered.). Since German grammar demands a preposition-determiner combination to be followed by a noun phrase, the immediate succession by a past participle represents an outright word category error. To ensure that participants could not anticipate the upcoming syntactic violation as soon as a preposition was encountered, a third category of syntactically correct filler sentences was presented, containing a complete noun phrase, as expected (e.g., Der Name wurde im Versteck geflüstert. The name was in-the cranny whispered.). Sentences were spoken by a professional female speaker (for a detailed description of stimulus preparation, see Hahne and Friederici, 1999). To provide participants with an easy timbre detection task, one word was occasionally spoken by a male voice (see below; Jentschke and Koelsch, 2009). During the experiment, participants listened to 132 correct, 132 incorrect, 66 filler sentences and 48 sentences containing a voice change; filler and sentences with voice change were excluded from the data analysis. Sentences were presented with a pause of $2 \mathrm{~s}$ between consecutive trials.

In the music experiment, participants listened to chord sequences ending either on a regular or an irregular chord function, as depicted in right panel of Fig. 1 (for the evaluation of these stimuli in healthy students, see Experiment 2A in Sammler, 2009). The initial five chord functions were identical in both sequence types: dominant [V] in sixth chord position - tonic [I] in root position - subdominant [IV] in sixth chord position - subdominant [IV] in root position dominant $[\mathrm{V}]$ in root position. In regular sequences, the final chord function was a tonic [I] (e.g., C-E-G in a C major sequence), irregular sequences ended on the major chord built on the lowered second degree of the scale [bII] (e.g., $\mathrm{D} b-\mathrm{F}-\mathrm{A} b$ in $\mathrm{C}$ major). According to the theory of harmony (Piston, 1948/1987; Schönberg, 1969), the tonic chord (as opposed to the bII) is the most regular and expected chord at the final position of these sequences. To avoid confounding brain potentials evoked by physical deviance due to the out-of-key notes in bII, all pitch classes of bII were inserted in the harmonic context as passing and auxiliary notes (see 8th notes in right panel of Fig. 1). Furthermore, sequences were composed such that bII introduced only one new pitch whereas the regular final tonic introduced two new pitches (see arrows in right panel of Fig. 1). Therefore, syntactically irregular bII were acoustically probably more similar to the previous harmonic context than syntactically regular tonic chords, allowing us to attribute brain responses evoked by the final bII to the processing of the syntactic, not acoustic, irregularity (for a discussion on the inter-relationship between music-syntactic and acoustic deviance, see Bharucha and Stoeckig, 1987; Bigand et al., 2003; Koelsch, 2012; Koelsch et al., 2007).

Chord sequences were created using Cubase SX 2.0 (Steinberg Media Technologies, Hamburg, Germany) and presented with grand piano sound (Steinberg, The Grand) in all 12 major keys. The presentation time of all chords was $500 \mathrm{~ms}$, except for the final chords, which had a duration of $1000 \mathrm{~ms}$ and were followed by a $500-\mathrm{ms}$ pause. Participants listened to 144 regular and 144 irregular sequences that were pseudorandomly intermixed so that two subsequent sequences were always presented in different tonal keys and not more than three sequences of the same type (regular/irregular) followed each other. To provide participants with an easy timbre detection task, another 36 sequences were included that contained one chord played by a deviant instrument (bells, VST sound a1); these sequences were excluded from the ERP analysis.

\section{Procedure}

The experiment was conducted at bedside. Stimuli were presented via headphones (Koss Porta Pro, Milwaukee, WI, USA) with a Laptop (HP compaq nx7010) using Presentation 0.70 (Neurobehavioral Systems, Inc., Albany, CA, USA). The patients were instructed to pay attention to the sentences and chord sequences and to press a button whenever they detected a deviant instrument or male voice. Patients

Table 2

Medical data of the patients.

\begin{tabular}{|c|c|c|c|c|c|c|}
\hline Patient & $\begin{array}{l}\text { Duration of } \\
\text { epilepsy }\end{array}$ & Diagnosis (ILAE) & Pathology & Medication & $\begin{array}{l}\text { Electrode } \\
\text { positions }\end{array}$ & $\begin{array}{l}\text { Days after } \\
\text { implantation }\end{array}$ \\
\hline P1 & 22 years & TLE with SPS/CPS evolving to GTC & Dysplasia, left hippocampus & $\begin{array}{l}1000 \text { mg Levetiracetam, } 1500 \mathrm{mg} \\
\text { Oxcarbazepin }\end{array}$ & $\begin{array}{l}\text { Left hemisphere } \\
6 \mathrm{~F}, 17 \mathrm{~T}, 9 \mathrm{P}\end{array}$ & 7 \\
\hline P2 & 7 years & $\begin{array}{l}\text { Symptomatic focal epilepsy with SPS/CPS } \\
\text { evolving to GTC }\end{array}$ & $\begin{array}{l}\text { Focal cortical dysplasia, left } \\
\text { temporo-mesial }\end{array}$ & 300 mg Oxcarbazepin & $\begin{array}{l}\text { Left } \\
\text { hemisphere } \\
4 \text { F, } 25 \text { T, } 3 \text { P }\end{array}$ & 5 \\
\hline P3 & 5 years & $\begin{array}{l}\text { Cryptogenic focal epilepsy with CPS } \\
\text { evolving to GTC }\end{array}$ & Normal & 400 mg Lamotrigin & $\begin{array}{l}\text { Left } \\
\text { hemisphere } \\
4 \text { F, } 23 \text { T, } 5 \text { P }\end{array}$ & 17 \\
\hline P4 & 9 years & TLE with SPS/CPS evolving to GTC & Normal & No medication & $\begin{array}{l}\text { Right hemisphere } \\
2 \text { F, } 28 \text { T, } 2 \text { P }\end{array}$ & 6 \\
\hline P5 & 50 years & $\begin{array}{l}\text { Symptomatic focal epilepsy with CPS } \\
\text { evolving to GTC }\end{array}$ & AHS, right & 1200 mg Oxcarbazepin & $\begin{array}{l}\text { Right } \\
\text { hemisphere } \\
7 \text { F, } 18 \text { T, } 7 \text { P }\end{array}$ & 17 \\
\hline
\end{tabular}

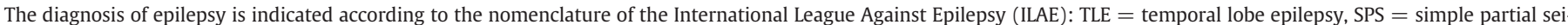

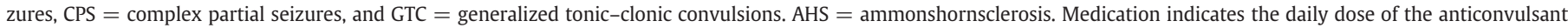

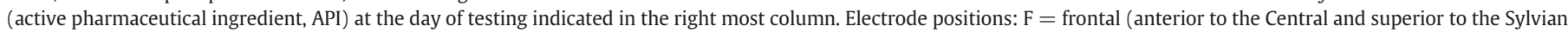
Fissure), $\mathrm{T}=$ temporal (inferior to the Sylvian Fissure), and $\mathrm{P}=$ parietal (posterior to the Central and superior to the Sylvian Fissure). 


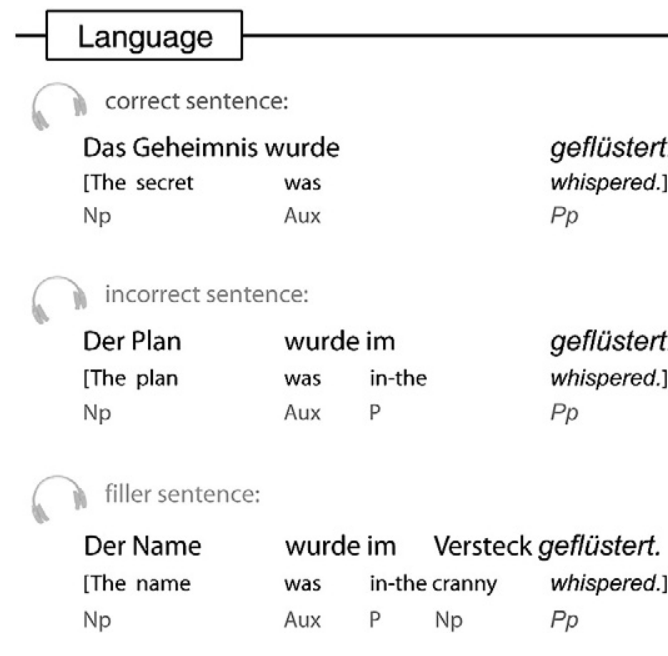

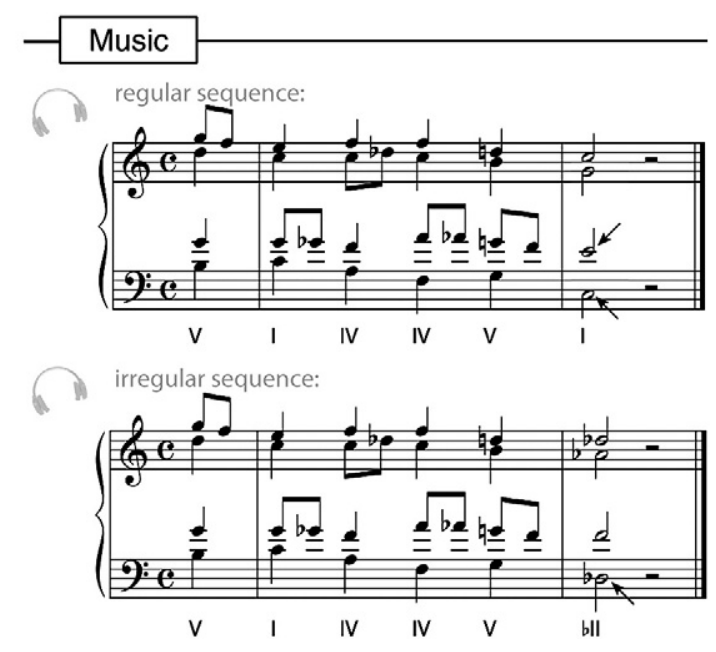

Fig. 1. Stimulus material employed in the language and music experiments.

were not informed about the syntactic violations. Music and language stimuli were presented separately in 12 short blocks with a duration of 3 min each. Music and language blocks alternated, counterbalanced across patients.

To test the patients' behavioral ability to explicitly discriminate syntactically correct and incorrect stimuli, a separate music and a language block was added at the end of the session during which patients were asked to indicate via button press, whether the final chord/word was regular/correct or irregular/incorrect. Participants' performance was tested during the random presentation of 24 regular and 24 irregular sequences in the music block, and 24 correct, 24 incorrect and 12 filler sentences in the language block. Patients were instructed to respond quickly within a 2-second time interval after the onset of the critical chord or word. In total, the EEG and behavioral experiment lasted approximately $90 \mathrm{~min}$. The research protocol was approved by the institutional review boards at the University Medical Center Freiburg and at the University Clinic in Bonn. Prior to the study, written informed consent was obtained from each patient.

\section{Data acquisition and analysis}

Data were collected at the Epilepsy Center of the University Medical Center Freiburg (Germany), as well as in the Clinic for Epileptology at the University Hospital in Bonn (Germany). The EEG signal was recorded from subdural grid and strip electrodes as well as from depth electrodes placed according to medical needs (Lesser et al., 2010). In Freiburg, EEG data were acquired with a Neurofile NT digital video EEG system (Natus Medical Incorporated, San Carlos, CA, USA). In Bonn, the data were recorded with the digital EPAS system and its implemented Harmonie EEG software (Natus Medical Incorporated, San Carlos, CA, USA). Depending on the amplifier, the data were sampled at 1000 or $1024 \mathrm{~Hz}$. For all patients, the exact locations of the electrodes were determined by means of co-registered and normalized preand postoperative magnetic resonance images with a resolution of $1 \times 1 \times 1 \mathrm{~mm}$ using the automated visualization method by Kovalev et al. (2005). Because most of the patients exhibited pathologies in the medial temporal lobe, only data from electrodes placed on lateral perisylvian brain areas were analyzed. Across patients, $69 \%(N=105)$ of the contacts were placed on the temporal, $15 \%(N=23)$ on the most inferior portion of the frontal, and $16 \%(N=25)$ on the parietal lobe.

Data processing was done with the in-house software EEP 3.2 (Nowagk and Pfeifer, 1996; commercially available as EEProbe from Advanced Neuro Technology, ANT, Enschede, Netherlands) and EEGlab 6.01 (Delorme and Makeig, 2004). In a first step, channels with aberrant inter-ictal activity or technical artifacts (mean $=1.4$ channels; range: 0-3 channels) were identified by an experienced epileptologist and excluded from the analysis. Data were re-referenced to a common average reference of the remaining electrodes of the grid, and the sampling rate in all data sets was adjusted to $500 \mathrm{~Hz}$ after antialias filtering with a 250-Hz low-pass filter (FIR, 241 or 247 points depending on the original sampling rate, Blackman window). Subsequently, data were filtered using a 0.4-Hz high-pass filter (FIR, 6931 points, Blackman window; to eliminate slow drifts and to adjust the baseline), and a 25-Hz low-pass filter (FIR, 213 points, Blackman window; to eliminate fast oscillations). Afterwards, data were visually inspected, and epochs containing inter-ictal activity or technical artifacts were manually rejected under supervision of an epileptologist. In a final step, data were averaged for each condition (regular chord, irregular chord, correct past participle, incorrect past participle) in a 1000-ms post-stimulus window.

One important issue for processing event-related electrophysiological data is baseline correction. Usually, a pre-stimulus baseline of several hundred milliseconds is used, e.g. -200 to $0 \mathrm{~ms}$ as in classical ERAN experiments (Koelsch et al., 2000). In the language experiment, because the word category prior to the participle differs (auxiliary vs. preposition), this approach could introduce offset effects, i.e. an artificial displacement of pre-onset word category effects into the ERP of the participle (Steinhauer and Drury, 2012). To overcome this difficulty, a high-pass filter $(0.4 \mathrm{~Hz}$; see above) was employed in both experiments, i.e. a baseline filter that removes unphysiological DC offsets (DC attenuation at $<-133 \mathrm{~dB}$ ) so that EEG signals are aligned to the zero potential line. Therefore, averaging of ERPs does not require further baseline correction (Friederici et al., 2000; Tervaniemi et al., 1999). The validity of this approach was verified by inspecting the auditory evoked potentials evoked at sentence onset (see Supplementary Fig. S1).

The ELAN and ERAN were calculated as difference potentials between ERPs following the irregular chord/incorrect past participle and ERPs following the regular chord/correct past participle (filler sentences were not

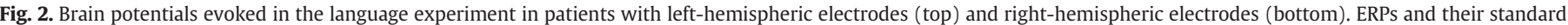

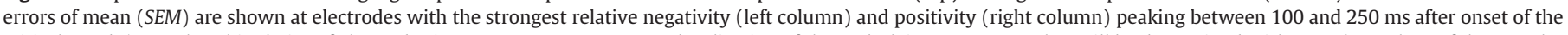

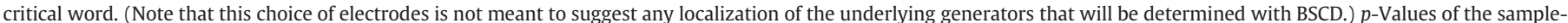

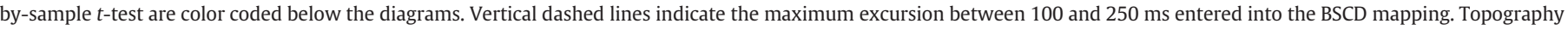

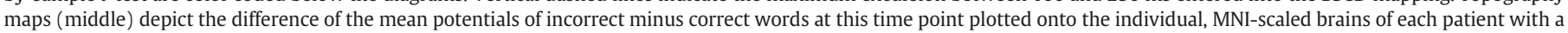

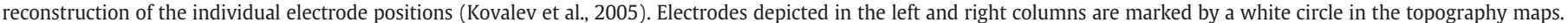



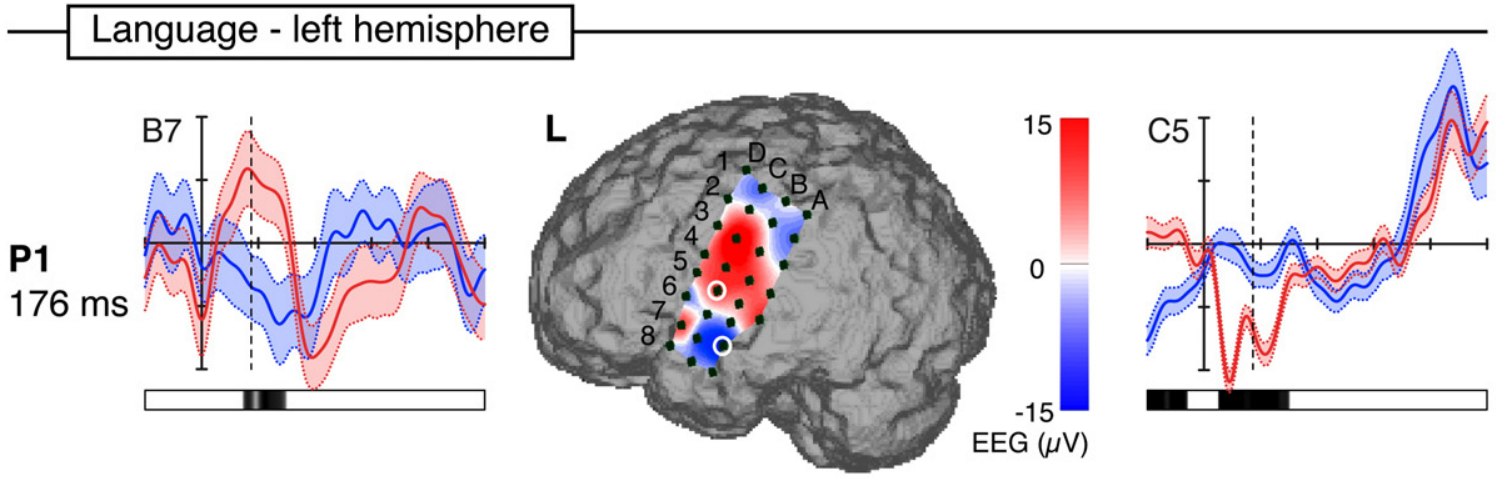

P2
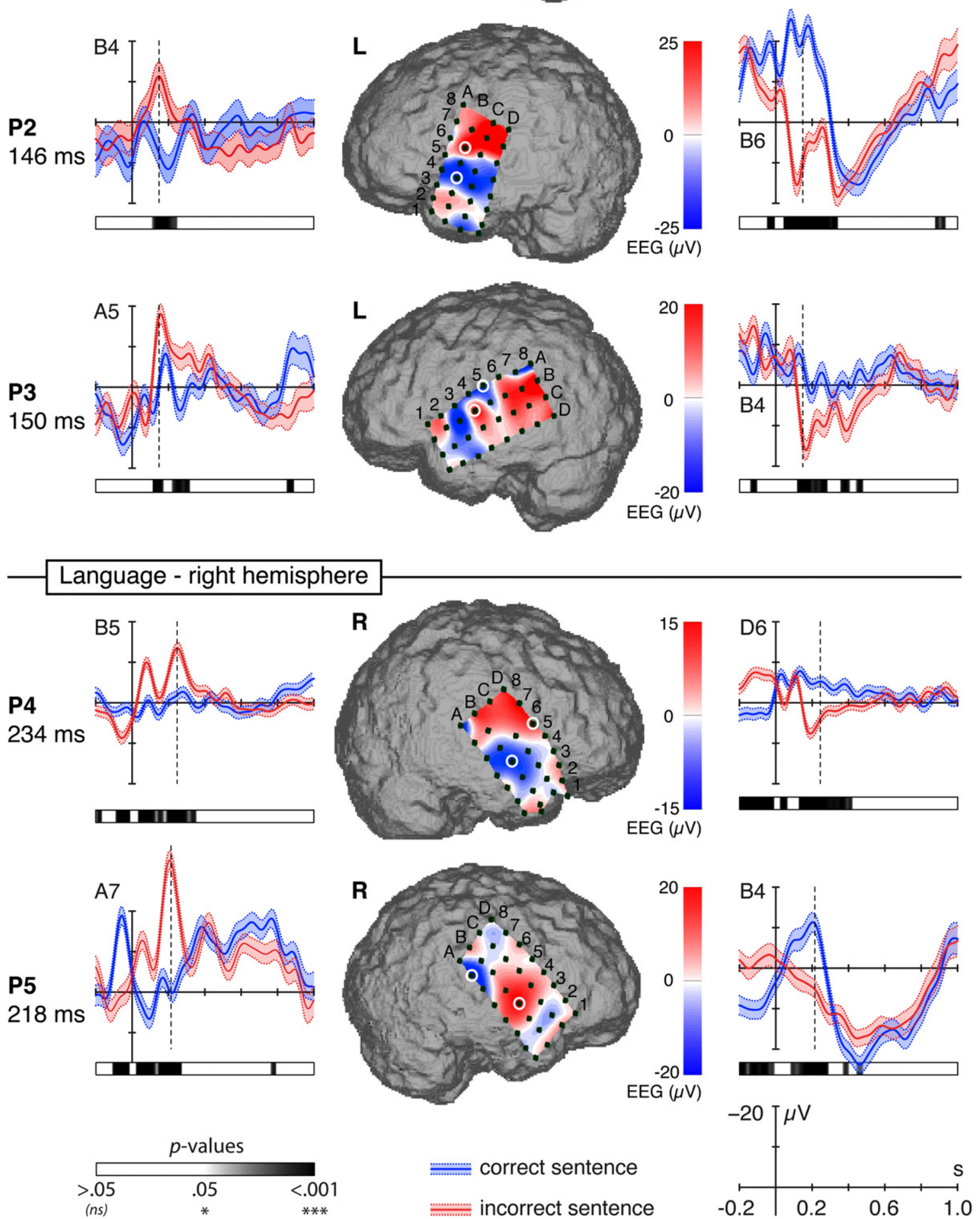
analyzed). Note that the labels ELAN and ERAN are employed irrespective of investigated hemisphere, in their function as a language and music related brain potential, respectively (see Introduction). The regular/correct and the irregular/incorrect conditions were compared in each patient individually by means of sample-by-sample $t$-tests (independent variables, unequal variance) with a criterion of $p<.05$ for a minimum of 15 consecutive samples (for a similar approach, see Gaillard et al., 2006). The relevant time point for source localization was identified as the peak latency of the greatest amplitude excursion across electrodes occurring between 100 and $250 \mathrm{~ms}$ after onset of the critical chord or word within the significant time windows. The time range from 100 to $250 \mathrm{~ms}$ was chosen based on a number of scalp EEG (Hahne and Friederici, 1999; Koelsch, 2009) and MEG studies (Friederici et al., 2000; Maess et al., 2001).

In a second processing step, Brain Surface Current Density mapping (BSCD; Ball et al., 1999; Knösche et al., 1996, 1999) was applied to reconstruct the distributed neural sources of the observed effects. Note that it is not possible to infer the localization of the sources from the topography of the local field potentials alone, e.g. half-way between a positive and a negative maximum, because the topography usually displays several positive and negative maxima (see Figs. 2 and 3) and it is not clear which of those are poles of the same dipole. BSCD mapping can solve this problem. This method is based on the Minimum Norm algorithm (Hämäläinen and Ilmoniemi, 1994; Ilmoniemi, 1991) and, in contrast to conventional dipole localization, does not require a priori knowledge on the nature and number of the generators, but allows to reconstruct distributed sources of arbitrary shape and extent within the assumed source space (for a comprehensive review on dipolar vs. distributed source models, see Michel et al., 2004). The source space of the BSCD method comprises the surface of the brain at a constant depth from the inner surface of the skull. This choice is particularly robust and does not need individual anatomical information on cortical folding. The depth information is sacrificed on purpose, because it is especially ill-determined by the data alone, if no plausible assumption on the shape of the sources (e.g., whether the source is point-like or focal) is possible. Compensation methods for this inevitable depth bias usually only work for small ranges of source shapes. Although methods can be tuned to yield localization errors of only a few millimeters also in depth direction for focal sources (Dümpelmann et al., 2009; Zhang et al., 2008), it is less likely that this can be generalized to arbitrary source geometries (see also Fuchs et al., 1999, 2007).

In general, one has to be aware that the electrode grid captures only a cutout of the brain activity during the task consequently leading to generator solutions including only parts of a possibly more widespread neural network. Therefore, the coverage of the perisylvian brain regions allows to find sources within the respective temporal brain areas, to a lesser extent also in inferior frontal and inferior parietal regions, but not in more dorsal structures or even contralateral brain areas (Dümpelmann et al., 2009). Moreover, it is important to note that the general spatial resolution of the reconstructed activity cannot exceed the spatial sampling of the intracranial EEG data, which does, however, not mean that particular features, such as peaks, cannot be localized with higher accuracy. In simulations using similar settings to the one used here, localization errors for single focal sources near the brain surface were quantified as below $5 \mathrm{~mm}$ by Zhang et al. (2008) and Fuchs et al. (2007). Similar results were reported by Dümpelmann et al. (2009).

BSCD mapping was applied on the peak of the difference waves between 100 and $250 \mathrm{~ms}$ after onset of the final word/chord using ASA 2.32 (ANT Software, Enschede, Netherlands; Zanow and Knösche, 2004). The volume conductor model was made up by one compartment for the cortical surface of the individual MNI-scaled brains. This subject-specific source space model was tessellated with 5168 triangles (7-mm edge length), reconstruction surface was defined in a depth of $7 \mathrm{~mm}$, and 2586 triplets of orthogonal dipoles were equidistantly placed on this surface (7-mm distance). Their magnitudes were computed using the minimum-norm leastsquares method. Magnitudes of the effect maxima were read out and z-transformed separately for the language and the music data with respect to the magnitudes of all dipoles in the respective hemisphere in each patient. MNI coordinates of effect maxima with $z$-values $\geq 3.09$ (corresponding to $p<.001$ ) were compared across the domains. Anatomical localizations of effect maxima were identified by an experienced neuroanatomist via visual inspection of the individual high-resolution anatomical scans.

\section{Results}

\section{Language}

Patients detected, on average, $99.17 \%$ of the voice deviants with an average false alarm rate of $0.48 \%$ showing that they had attended to the stimulus material. All patients performed well above chance level when asked to detect the syntactic errors within the sentences, as assessed in the final behavioral block of the session (mean: $97.08 \%$, SD: $4.32 \%$, range: $89.58-100 \%$ ), showing the patients' sensitivity to the syntactic errors (Table 3 ).

In all participants, word category violations elicited an early negativity as well as a simultaneous early positivity with a mean peak latency of $185 \mathrm{~ms}$ after onset of the critical word (Fig. 2). This effect was found irrespective of whether electrodes were implanted in the left or the right hemisphere, although it peaked earlier at left (mean: $157 \mathrm{~ms}$ ) compared to right recording sites (mean: $226 \mathrm{~ms}$ ).

The BSCD mapping showed major sources of brain activity along the superior and middle temporal gyrus (STG/MTG) in all patients, extending into adjacent postcentral (PCG; P1, P2) and inferior frontal gyrus (IFG; P1) as well as inferior parietal brain areas (P3) depending on the extent of grid coverage (left panel of Fig. 4). Table 4 summarizes the MNI coordinates of the local source maxima separately for each patient.

An additional effect peaking at $70 \mathrm{~ms}$ after onset of the participle, i.e. before the ELAN time window, was found in patients with righthemispheric electrodes. Furthermore, a number of electrodes showed pre-onset differences between correct and incorrect conditions that are most likely due to the different word categories (auxiliary vs. preposition) preceding the critical past participle. Note that these differences are desired consequences of our baseline filter (see Material and methods and Discussion) to avoid offset effects (Steinhauer and Drury, 2012).

\section{Music}

Patients detected an average of $97.78 \%$ of the deviant instruments with a $0.27 \%$ false alarm rate, showing that they had attended to the stimuli. When asked to discriminate regular and irregular sequences (as assessed in the final block of the experiment), patients performed on average at $77.08 \%$ (SD: $18.46 \%$, range: $50-97.92 \%$ ). Four patients performed above chance, P5 was at chance level as revealed by binomial tests (Table 3 ).

In all patients, irrespective of whether the electrodes were placed in the left or right hemisphere, we observed an early negativity as well as a simultaneous early positivity with a mean peak latency of $188 \mathrm{~ms}$ after onset of the irregular chords (range: 166-204 ms; Fig. 3). These effects were found to peak slightly earlier in right-hemispheric (mean: $171 \mathrm{~ms}$ ) compared to left-hemispheric recordings (mean: $199 \mathrm{~ms}$ ). 

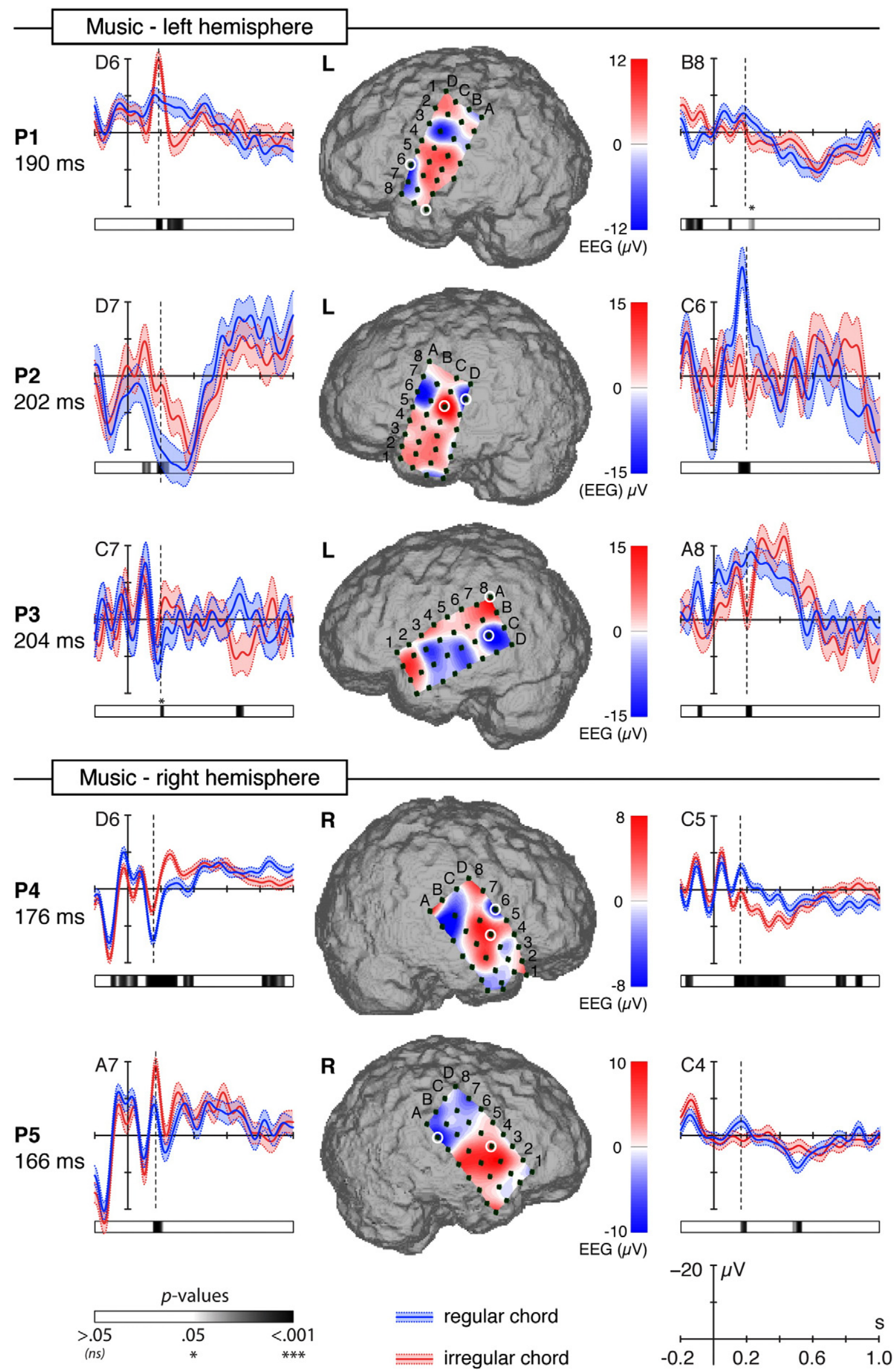
Table 3

Behavioral performance of each patient in the language and the music experiment.

\begin{tabular}{|c|c|c|c|c|}
\hline \multirow[t]{2}{*}{ Patient } & \multicolumn{2}{|l|}{ Language } & \multicolumn{2}{|l|}{ Music } \\
\hline & \%Correct & $p$-Value & \%Correct & $p$-Value \\
\hline \multicolumn{5}{|c|}{ Left-hemispheric electrodes } \\
\hline P1 & $100.00 \%$ & $<.001$ & $77.08 \%$ & $<.001$ \\
\hline P2 & $89.58 \%$ & $<.001$ & $97.92 \%$ & $<.001$ \\
\hline P3 & $100.00 \%$ & $<.001$ & $70.83 \%$ & $<.001$ \\
\hline \multicolumn{5}{|c|}{ Right-hemispheric electrodes } \\
\hline P4 & $97.92 \%$ & $<.001$ & $89.58 \%$ & $<.001$ \\
\hline P5 & $97.92 \%$ & $<.001$ & $50.00 \%$ & $>.440$ \\
\hline
\end{tabular}

$p$-Values indicate whether patients performed above $(p<.05)$ or below $(p>.05)$ chance level (50\%).

Like in the language experiment, the BSCD mapping revealed distributed generators along the STG and MTG in all patients, extending into the adjacent PCG (P1) and pars opercularis of the IFG (P1, P2, P5; right panel of Fig. 4 and Table 4).

\section{Language vs. music}

Patients' performance in detecting deviant voices and instruments did not differ (Wilcoxon signed ranks test: $Z(4)=-0.82 ; p>.414$ ). Nominally, patients appeared to perform better in detecting syntactic errors in sentences than irregular chords in music, however, this difference did not reach statistical significance as only 4 out of the 5 patients showed better performance for language than for music violations (Wilcoxon signed ranks test: $Z(4)=-1.63 ; p=.103$ ).

Within each single patient, the BSCD mapping revealed considerable overlap during the processing of word category and musical harmony violations (compare left and right panels of Fig. 4). Neural sources were overall stronger and more extended during the language than the music experiment (compare nAm in Table 4). Closer inspection revealed an average of 3.7 (range: $2-7$ ) significant source maxima in each participant (out of 1293 possible maxima per hemisphere) that were subsequently compared to estimate the precision of the overlap (Table 4). Particular correspondence between the coordinates of source maxima was observed in the anterior (P1, P3), mid (P2, P4, P5), or posterior STG (P4, P5). The variable position of source maxima along the $y$-axis of the STG may be accounted for by the natural variability of brain anatomy and the uniqueness of grid position in the single subjects (Cohen et al., 2004; Frost and Goebel, 2012; Korzyukov et al., 2007; Ojemann, 1979). Furthermore, P1 showed additional overlap in the left IFG and PCG, and P3 exhibited similar sources in the left IPL and SMG. The examination of all effect maxima demonstrated that the Euclidian distance between sources in music and language was on average $3.6 \mathrm{~mm}$, ranging from 0 to $9.27 \mathrm{~mm}$ (Table 4). Within the spatial resolution of approx. $7 \mathrm{~mm}$ given in the present study (see Materials and methods) this indicates that brain potentials in both domains were generated by identical or immediately adjacent dipoles.

In addition to this result, the extracted source maxima show that the overlap between the two processing domains was not complete. A subset of generators in the language experiment - mainly additional activation peaks in the temporal lobe - did not have correspondent maxima in the music domain, not even at a lowered threshold of $z \geq 2.33$ or $z \geq 1.65$ (corresponding to $p<.01$ and $p<.05$, respectively). Conversely, the music experiment evoked additional frontal activity in three patients (P2, P5, and at a lowered threshold also in P3) that was not observed in the language experiment. Note that parts of the pars opercularis of the IFG and the PrCG were covered in all patients with an average of 4.6 electrodes (range: $2-7$; see Table 2 ) making it principally possible to capture some activity of the most inferior portion of the frontal lobe, i.e. the location thought to host generators of the scalp-recorded ELAN (Friederici et al., 2000) and ERAN (Maess et al., 2001). Taken together, the generators of the ELAN and ERAN differed with regard to the relative weighting of temporal and frontal lobe involvement, with stronger weights in the temporal cortex for language and stronger weights in the frontal cortex for music violations.

Apart from that, the latency of music- and language-related effects appeared to differ depending on the side of implantation. Languagerelated potentials peaked earlier in left-hemispheric contacts, whereas music-related potentials peaked earlier in right-hemispheric contacts (Fig. 5). This observation was statistically significant (Pearson's Chi-square test: $\chi^{2}(4)=5, p<.026$ ) and is in line with the assumed differential hemispheric weighting of syntax processing in language and music (Maess et al., 2001).

\section{Discussion}

The present study investigated the neuroanatomical co-localization of musical and linguistic syntax processing by means of subdural recordings in a within-subject design. The combined data demonstrate that the detection of syntactic violations in music and speech relies on partly overlapping, bilateral temporo-fronto-parietal neural networks that differ, however, in the timing and relative weighting of their constituents.

\section{Domain-general resources}

Both word category violations in sentences and harmonic irregularities in chord progressions elicited early negativities and simultaneous positivities with a peak latency of about $200 \mathrm{~ms}$. These electrophysiological potentials are consistent with the latency and the typical polarity inversion of the scalp-recorded ELAN and ERAN at mastoid leads when referenced to nose electrode (Hahne and Friederici, 1999; Koelsch, 2009; Koelsch et al., 2000; Maidhof and Koelsch, 2011), suggesting that the observed effects represent electrocortical equivalents of the scalp-recorded ELAN and ERAN.

In both language and music experiments, BSCD mapping identified sources of the ELAN and ERAN within superior temporal, and partly inferior frontal and parietal brain areas. A number of MEG and fMRI studies have reported the involvement of STG, IFG and frontal operculum in the processing of word category violations (Brauer and Friederici, 2007; Friederici et al., 1999, 2000, 2003; Knösche et al., 1999; Rüschemeyer et al., 2005). Likewise, the involvement of the IFG, anterior insula, ventral PrCG, and STG has been frequently shown during the processing of harmonic irregularities (Kim et al., 2011; Koelsch et al., 2001, 2002, 2005b; Maess et al., 2001; Minati et al., 2008; Sammler et al., 2011; Tillmann et al., 2003, 2006), and the processing of music-syntactic relations in melodies (Krumhansl, 2004; Platel et al., 1997; Schmithorst, 2005; Zatorre et al., 1994). Finally, also the supramarginal gyrus and inferior parietal lobe are well-known constituents of the neural networks processing musical (Foster and Zatorre, 2010; Koelsch et al., 2005b; Platel et al., 1997; Schmithorst, 2005; Tillmann et al., 2003) and linguistic material (Bahlmann et al., 2007; Corina et al., 1999; Demonet et al., 2005; Price, 2010; Ravizza et al., 2004), most often associated with working memory for pitch (Gaab et al., 2003; Koelsch et al., 2009; Schulze et al., 2011; Vines et al., 2006) and working memory for verbal information (Buchsbaum and D'Esposito, 2009; Henson et al., 2000; Hickok et al., 2003; Paulesu et al., 1993).

The within-subject comparisons of the BSCD mapping of both experiments revealed a noticeable overlap of parts of the individual networks in the processing of musical and linguistic syntax with major convergence zones in the temporal lobe, as predicted. Within the spatial resolution of the reconstructed activity, local effect maxima in music and language were consistently observed at identical or immediately adjacent coordinates lending support for the hypothesis of temporal brain regions that process musical and linguistic irregularities in a 

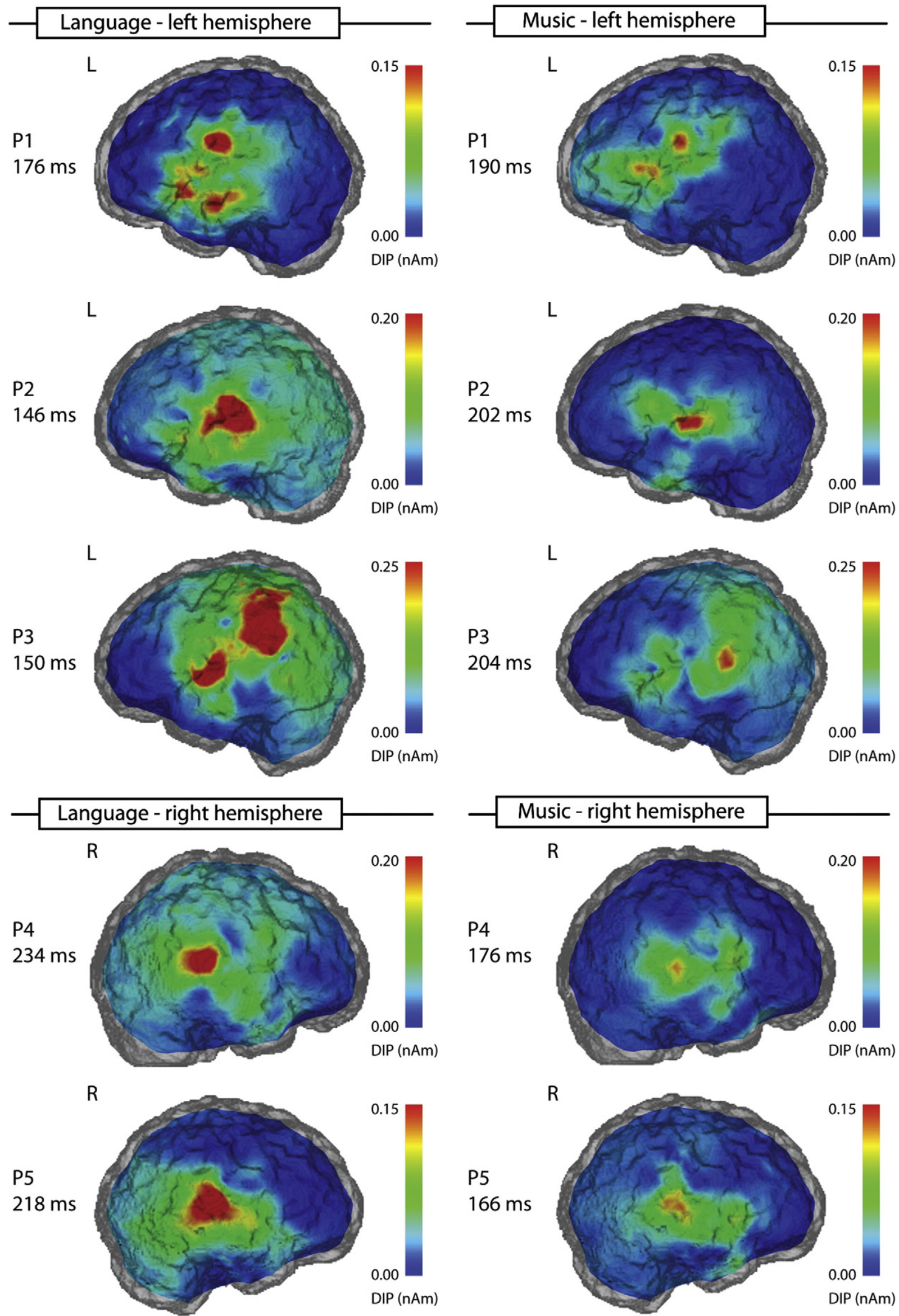

Fig. 4. Results of the Brain Surface Current Density (BSCD) mapping in the language experiment (left panel) and the music experiment (right panel). 
Table 4

MNI coordinates of the local source maxima obtained in the BSCD mapping.

\begin{tabular}{|c|c|c|c|c|c|c|c|c|c|c|c|c|c|c|c|}
\hline \multirow[t]{2}{*}{ Patient } & \multicolumn{7}{|l|}{ Language } & \multicolumn{7}{|l|}{ Music } & \multirow[t]{2}{*}{ Euclidian distance } \\
\hline & Region & BA & $\mathrm{x}$ & $\mathrm{y}$ & $\mathrm{z}$ & $\mathrm{nAm}$ & z-value & Region & BA & $\mathrm{x}$ & $\mathrm{y}$ & $\mathrm{z}$ & $\mathrm{nAm}$ & z-value & \\
\hline \multicolumn{16}{|c|}{ Left-hemispheric electrodes } \\
\hline \multirow[t]{7}{*}{ P1 } & PCG & $1 / 2 / 3$ & -59 & -12 & 21 & 0.22 & 6.47 & PCG & $1 / 2 / 3$ & -59 & -12 & 21 & 0.15 & 6.59 & 0.00 \\
\hline & IFG, p.op. & 44 & -52 & 15 & 4 & 0.13 & 3.27 & IFG, p.op. & 44 & -52 & 15 & 4 & 0.14 & 5.94 & 0.00 \\
\hline & aSF & - & -56 & 0 & 4 & 0.13 & 3.69 & $\mathrm{aSF}$ & - & -54 & 5 & 1 & 0.13 & 5.62 & 6.14 \\
\hline & aSF & - & -51 & 14 & -6 & 0.14 & 4.08 & & & & & & & & - \\
\hline & aSTG & 22 & -53 & 7 & -12 & 0.16 & 4.57 & & & & & & & & - \\
\hline & mMTG & 21 & -62 & -19 & -12 & 0.13 & 3.70 & & & & & & & & - \\
\hline & mMTG & 21 & -59 & -9 & -18 & 0.15 & 4.34 & & & & & & & & - \\
\hline \multirow[t]{6}{*}{ P2 } & mSTG & 22 & -62 & -18 & 6 & 0.25 & 5.98 & mSTG & 22 & -61 & -13 & -1 & 0.21 & 7.69 & 8.66 \\
\hline & mSTG & 22 & -63 & -26 & 4 & 0.24 & 5.64 & $\mathrm{mSTG}$ & 22 & -63 & -22 & 2 & 0.22 & 7.80 & 4.47 \\
\hline & mSTG & 22 & -59 & -5 & 3 & 0.22 & 4.97 & & & & & & & & - \\
\hline & PCG & $1 / 2 / 3$ & -61 & -15 & 18 & 0.24 & 5.53 & & & & & & & & - \\
\hline & & & & & & & & IFG, p.op./PrCG & $44 / 6$ & -55 & 9 & 15 & 0.12 & 4.09 & - \\
\hline & & & & & & & & IFG, p.op./PrCG & $44 / 6$ & -55 & 7 & 8 & 0.12 & 4.04 & - \\
\hline \multirow[t]{7}{*}{ P3 } & SMG & 40 & -59 & -41 & 27 & 0.52 & 6.46 & $S M G$ & 40 & -57 & -48 & 32 & 0.14 & $2.98^{a}$ & 8.83 \\
\hline & IPL & 7 & -45 & -47 & 48 & 0.31 & 3.48 & IPL & 7 & -45 & -47 & 48 & 0.10 & $1.82^{b}$ & 0.00 \\
\hline & IPL & 7 & -46 & -39 & 50 & 0.29 & 3.20 & & & & & & & & - \\
\hline & aSTG & 22 & -57 & -2 & -7 & 0.34 & 3.93 & aSTG & 22 & -57 & -2 & -7 & 0.17 & 3.94 & 0.00 \\
\hline & mSTG & 22 & -59 & -11 & 3 & 0.37 & 4.35 & & & & & & & & - \\
\hline & & & & & & & & pMTG & 21 & -62 & -42 & 4 & 0.24 & 6.42 & - \\
\hline & & & & & & & & $\operatorname{PrCG}$ & 6 & -56 & 3 & 13 & 0.10 & $1.81^{b}$ & - \\
\hline \multicolumn{16}{|c|}{ Right-hemispheric electrodes } \\
\hline \multirow[t]{2}{*}{ P4 } & pSTG & 22 & 65 & -33 & 12 & 0.26 & 8.39 & pSTG & 22 & 66 & -31 & 3 & 0.17 & 7.16 & 9.27 \\
\hline & mSTG & 22 & 66 & -22 & -7 & 0.12 & $2.92^{a}$ & mSTG & 22 & 66 & -19 & -2 & 0.12 & 4.57 & 5.83 \\
\hline \multirow[t]{5}{*}{ P5 } & pSTG & 22 & 67 & -36 & 6 & 0.19 & 6.44 & pSTG & 22 & 67 & -36 & 6 & 0.10 & 4.78 & 0.00 \\
\hline & $\mathrm{mSTG}$ & 22 & 67 & -26 & 3 & 0.19 & 6.34 & $\mathrm{mSTG}$ & 22 & 67 & -26 & 3 & 0.13 & 6.74 & 0.00 \\
\hline & mSTG & 22 & 68 & -26 & 13 & 0.18 & 5.88 & & & & & & & & - \\
\hline & mSTG & 22 & 62 & -6 & -6 & 0.11 & 3.20 & & & & & & & & - \\
\hline & & & & & & & & IFG, p.op. & 44 & 55 & 13 & -5 & 0.10 & 4.78 & - \\
\hline
\end{tabular}

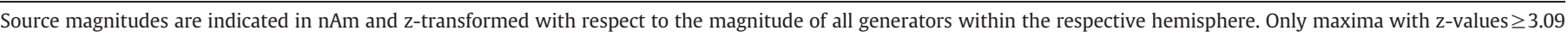

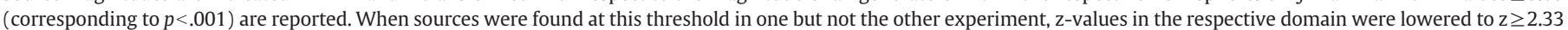

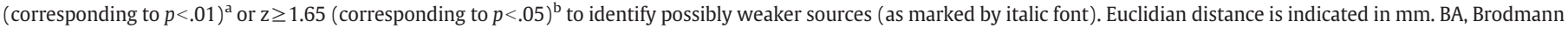

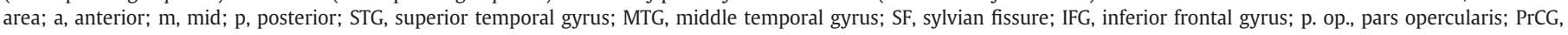

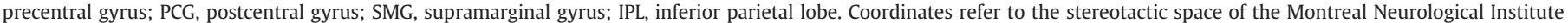
(Evans et al., 1994; Mazziotta et al., 1995).

domain-general way (Koelsch, 2005; Patel, 2003, 2008). The putative shared role of the temporal lobe might be to identify the syntactic status of each incoming item, such as word category (Hagoort, 2009; Indefrey and Levelt, 2004; Snijders et al., 2009) or chord function (Klein and Zatorre, 2011), and to match it with local syntactic expectancies in cooperation with the inferior frontal lobe.

Overall, this role of the temporal lobe integrates into the framework of predictive coding as a domain-general principle of brain organization (Friston, 2002, 2010). This model proposes a hierarchical cognitive architecture whereby lower-level brain areas (e.g. the temporal

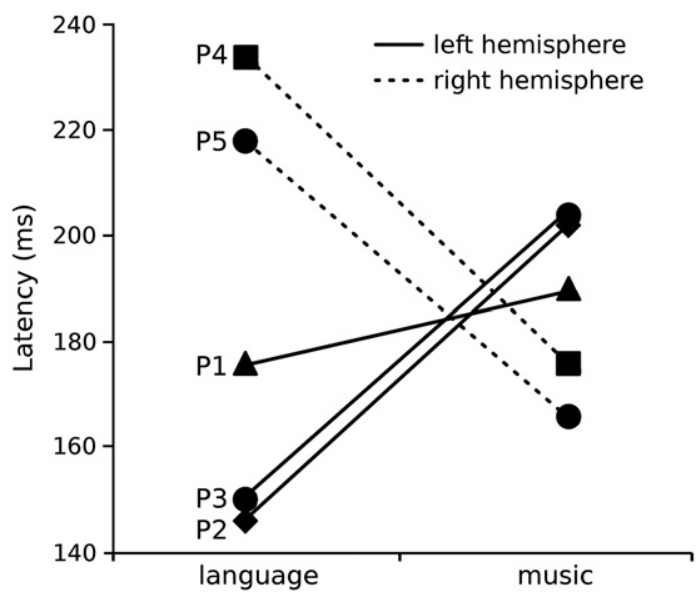

Fig. 5. Latency differences of language- and music-related ERPs depending on the site of implantation. lobe) estimate the input within contextual constraints provided from higher-level areas via backward connections. A mismatch between the contextually predicted and truly perceived input produces an error signal (e.g., the ELAN and ERAN) that may lead to the revision of higher-level representations (e.g., the so far established syntactic phrase-structure or tonality) via forward connections. Translated to syntax in music and language, both stimuli trigger an interactive process of higher-order prediction based on the rule-based regularities of the surroundings and lower-level validation of these predictions, i.e. the matching of each item of the incoming auditory sequence against an expected syntactic form (see also Vuust et al., 2009). The present data are not suited to comment on higher-level processes (and primarily address the processing of syntactic violations as opposed to regular material, for discussion see Rogalsky et al., 2011). However, they suggest that some of the mentioned low-level matching processes may not only exert functional similarity across the music and language domain but also indeed rely on partly shared neuroanatomical resources in the superior temporal lobe.

\section{Between-domain differences}

Despite the partial overlap of brain activations in music and language, a subset of generators in the language experiment - mainly additional activation peaks in the temporal lobe - did not find corresponding maxima in the music domain, whereas the music experiment evoked additional frontal activity (owing to the placement of a few electrodes on the most inferior portion of the pars opercularis of the IFG and the PrCG) that was not observed in the language experiment. Note, however, that this does not rule out frontal lobe involvement in the language 
experiment (see P1), as the recordings may have been essentially blind to activity from ELAN-related sources beyond electrode coverage.

As far as the unequal frontal (15\% of contacts) and temporal electrode coverage (69\% of contacts) allows to say, these data may suggest that the neural networks involved in the generation of the ELAN and ERAN differ with respect to the relative weighting of their temporal and frontal constituents. A putative temporal predominance in the language experiment converges with the results of previous MEG and fMRI studies that consistently observed stronger temporal than frontal activity during local syntactic processing (e.g., Friederici et al., 2000, 2003; Herrmann et al., 2009, 2011b) (for a review, see Kaan and Swaab, 2002), while music syntax research very much focused on the preeminent role of the frontal lobe (Koelsch et al., 2005b; Levitin and Menon, 2003; Maess et al., 2001; Sammler et al., 2011). This different weighting might reflect a different degree of automaticity (Maidhof and Koelsch, 2011) as endorsed by the behavioral data and by fMRI studies showing a shift of linguistic syntax processing from the frontal lobe (suggesting the involvement of controlled processes) to the temporal lobe with increasing language proficiency (Brauer and Friederici, 2007; Rüschemeyer et al., 2005). In this context, the choice of experimental paradigms is an issue that deserves consideration and is more extensively discussed below.

Apart from a different fronto-temporal weighting, language potentials exhibited shorter latencies in the left hemisphere, while music potentials peaked earlier in right-hemispheric recordings. Although based on between-subjects comparisons, this differential hemispheric timing fits with prevailing models that claim a relative specialization of the left and right hemisphere for linguistic and musical stimulus features, respectively, such as segmental and suprasegmental (Friederici and Alter, 2004) or temporal and spectral information (Zatorre et al., 2002). In other words, the time course of brain activity within spatially overlapping neural resources may determine their relative specialization for language or music.

Furthermore, syntactic violations in language (but not music) evoked an additional effect peaking at $70 \mathrm{~ms}$ after onset of the participle (i.e. before the ELAN time window) in patients with right-hemispheric electrodes. This negativity is reminiscent of the very early effects observed by Herrmann et al. (2009) or Pulvermüller et al. (2008) between 40 and $80 \mathrm{~ms}$ in syntactic mismatch negativity paradigms. According to these studies, the effect might correspond to a modulation of the P50 a component that has been associated with auditory arousal, preferential attention to sensory inputs and "gating in" of relevant information (Herrmann et al., 2009, 2011a). The fact that the P50 was modulated by the syntactic category of the words might reflect the tuning of auditory areas towards the morpheme "ge-" of the participle that could be used as a form-based indicator of syntactic category in the present stimulus material (for similar findings in the visual modality, see Dikker et al., 2009).

Finally, in the language, but not the music experiment, a number of electrodes showed pre-onset differences between correct and incorrect conditions that are most likely due to the different word categories (auxiliary vs. preposition) preceding the critical past participle (left panel of Fig. 1). This point has recently been subject to critique (Steinhauer and Drury, 2012) stating that the ELAN may merely reflect the tail of pre-onset word category effects (i.e. spill-over effects) or the spurious displacement of pre-onset effects to the ELAN time window and beyond due to baseline correction (i.e. offset effects). In the present study, we avoided offset effects using a baseline filter (see Material and methods and Supplementary Fig. S1 for validation of the filter) rather than forcing the potentials together as usually done in a conventional baseline correction. Consequently, differences are visible prior to participle onset, but are not transferred into the critical time window. Notably, and incompatible with a spill-over effect, potentials at each electrode inverted polarity at the onset of the participle. This pattern is in line with the onset of a new cognitive operation (Michel et al.,
2004), most likely related to the phrase-structure violations in the employed sentence material.

\section{Choice of paradigms}

A general challenge in between-domain comparative research is the choice of experimental paradigms and the assertion that those trigger supposedly analogous cognitive processes in the two domains. What is the language equivalent of a harmonic violation in chord sequences? We chose word category and harmonic violations - both local syntactic violations - based on the temporal, morphological and conceptual similarities of the ELAN and ERAN, i.e. being an "error signal" evoked whenever the predicted word or chord category does not match the expected input (see Introduction). Moreover, the ELAN and ERAN have been shown to partly interact in interference paradigms (Maidhof and Koelsch, 2011), in line with the overlap observed in the present study.

On the other hand, it could be argued that a very local analysis of the prepositional phrase may have been sufficient to detect the phrasestructure violations (Hagoort, 2009; Pulvermüller, 2002), whereas the detection of the music-syntactic violations depended on the analysis of local dependencies and the integration of harmonic functions across an extended musical context alike (Bigand and Parncutt, 1999; Garza Villarreal et al., 2011; Koelsch, 2011, 2012). Note that such a difference in processing complexity naturally reduces the chance to find complete overlap in a direct comparison but allows attributing the partial overlap to the smallest common denominator of the two paradigms: shared aspects of local syntactic analysis in music and language, as initially hypothesized. The co-localization of higher-order syntactic processes remains an interesting topic for future research.

\section{Conclusion}

In sum, the within-subject comparison of perisylvian electrocortical potentials demonstrates that local syntactic processes in music and language are subserved by partially shared neuroanatomical regions that differ however in their relative weighting and timing. Areas of main overlap were found in the bilateral superior temporal lobe in agreement with the hypothesis that musical and linguistic syntax processing share low-level mechanisms that match the perceived information with the contextually predicted input, and thus contribute to the establishment of a coherent mental representation of the musical and linguistic structure.

Supplementary data to this article can be found online at http:// dx.doi.org/10.1016/j.neuroimage.2012.09.035.

\section{Acknowledgments}

First and foremost, we thank all the patients who participated in this study. We further thank the clinical teams of the epilepsy units in Freiburg and Bonn for their great help with organizing the data collection, Dr. Dirk Altenmüller for his expertise in identifying epileptic artifacts, Dr. Derek V. M. Ott for localization of effect maxima, and Sven Gutekunst for technical support.

\section{References}

Abrams, D.A., Bhatara, A., Ryali, S., Balaban, E., Levitin, D.J., Menon, V., 2011. Decoding temporal structure in music and speech relies on shared brain resources but elicits different fine-scale spatial patterns. Cereb. Cortex 21, 1507-1518.

Bahlmann, J., Rodriguez-Fornells, A., Rotte, M., Munte, T.F., 2007. An fMRI study of canonica and noncanonical word order in German. Hum. Brain Mapp. 28, 940-949.

Ball, T., Schreiber, A., Feige, B., Wagner, M., Lucking, C.H., Kristeva-Feige, R., 1999. The role of higher-order motor areas in voluntary movement as revealed by highresolution EEG and fMRI. Neurolmage 10, 682-694.

Ball, T., Kern, M., Mutschler, I., Aertsen, A., Schulze-Bonhage, A., 2009. Signal quality of simultaneously recorded invasive and non-invasive EEG. NeuroImage 46, 708-716.

Bharucha, J.J., Stoeckig, K., 1987. Priming of chords - spreading activation or overlapping frequency-spectra. Percept. Psychophys. 41, 519-524. 
Bigand, E., Parncutt, R., 1999. Perceiving musical tension in long chord sequences. Psychol. Res. 62, 237-254.

Bigand, E., Poulin, B., Tillmann, B., Madurell, F., D'Adamo, D.A., 2003. Sensory versus cognitive components in harmonic priming. J. Exp. Psychol. Hum. 29, 159-171.

Bookheimer, S., 2002. Functional MRI of language: new approaches to understanding the cortical organization of semantic processing. Annu. Rev. Neurosci. 25, 151-188.

Brauer, J., Friederici, A.D., 2007. Functional neural networks of semantic and syntactic processes in the developing brain. J. Cogn. Neurosci. 19, 1609-1623.

Brown, S., Martinez, M.J., Parsons, L.M., 2006. Music and language side by side in the brain: a PET study of the generation of melodies and sentences. Eur. J. Neurosci. 23, 2791-2803.

Buchsbaum, B.R., D'Esposito, M., 2009. Repetition suppression and reactivation in auditoryverbal short-term recognition memory. Cereb. Cortex 19, 1474-1485.

Bullock, T.H., Mcclune, M.C., Achimowicz, J.Z., Iraguimadoz, V.J., Duckrow, R.B., Spencer, S.S., 1995. EEG coherence has structure in the millimeter domain - subdural and hippocampal recordings from epileptic patients. Electroencephalogr. Clin. Neuro. $95,161-177$

Chomsky, A.N., 1957. Syntactic Structures. Mouton, Den Haag.

Chomsky, A.N., 1995. The Minimalist Program. MIT Press, Cambridge, MA.

Cohen, L., Jobert, A., Le Bihan, D., Dehaene, S., 2004. Distinct unimodal and multimodal regions for word processing in the left temporal cortex. NeuroImage 23, 1256-1270.

Corina, D.P., McBurney, S.L., Dodrill, C., Hinshaw, K., Brinkley, J., Ojemann, G., 1999. Functional roles of Broca's area and SMG: evidence from cortical stimulation mapping in a deaf signer. Neurolmage 10, 570-581.

Darwin, C., 1871/1989. The Descent of Man, and Selection in Relation to Sex. New York University Press, New York

Delorme, A., Makeig, S., 2004. EEGLAB: an open source toolbox for analysis of single-trial EEC dynamics including independent component analysis. J. Neurosci. Methods 134, 9-21.

Demonet, J.F., Thierry, G., Cardebat, D., 2005. Renewal of the neurophysiology of language: functional neuroimaging. Physiol. Rev. 85, 49-95.

Dikker, S., Rabagliati, H., Pylkkänen, L., 2009. Sensitivity to syntax in visual cortex. Cognition 110, 293-321.

Dümpelmann, M., Fell, J., Wellmer, J., Urbach, H., Elger, C.E., 2009. 3D source localization derived from subdural strip and grid electrodes: a simulation study. Clin. Neurophysiol. $120,1061-1069$.

Eckstein, K., Friederici, A.D., 2006. It's early: event-related potential evidence for initial interaction of syntax and prosody in speech comprehension. J. Cogn. Neurosci. 18, $1696-1711$

Evans, A., Kamber, M., Collins, D.L., MacDonald, D., 1994. An MRI-based probabilistic atlas of neuroanatomy. In: Shorvon, S., Fish, D., Anderman, F., Byder, G.M., Stefan, H. (Eds.), Magnetic resonance scanning and epilepsy. Plenum Press, New York, pp. 263-274.

Fadiga, L., Craighero, L., D'Ausilio, A., 2009. Broca's area in language, action, and music. Ann. N. Y. Acad. Sci. 1169, 448-458.

Fedorenko, E., Patel, A., Casasanto, D., Winawer, J., Gibson, E., 2009. Structural integration in language and music: evidence for a shared system. Mem. Cogn. 37, 1-9.

Fedorenko, E., Behr, M.K., Kanwisher, N., 2011. Functional specificity for high-level linguistic processing in the human brain. Proc. Natl. Acad. Sci. U.S.A. 108 (39), $16428-16433$.

Fedorenko, E., Nieto-Castañón, A., Kanwisher, N., 2012. Syntactic processing in the human brain: what we know, what we don't know, and a suggestion for how to proceed. Brain Lang. 120, 187-207.

Fiebach, C.J., Schubotz, R.I., 2006. Dynamic anticipatory processing of hierarchical sequential events: a common role for Broca's area and ventral premotor cortex across domains? Cortex 42, 499-502.

Foster, N.E.V., Zatorre, R.J., 2010. A role for the intraparietal sulcus in transforming musical pitch information. Cereb. Cortex 20, 1350-1359.

Friederici, A.D., 2002. Towards a neural basis of auditory sentence processing. Trends Cogn. Sci. 6, 78-84

Friederici, A.D., 2009. Pathways to language: fiber tracts in the human brain. Trends Cogn. Sci. 13, 175-181.

Friederici, A.D., Alter, K., 2004. Lateralization of auditory language functions: a dynamic dual pathway model. Brain Lang. 89, 267-276.

Friederici, A.D., Pfeifer, E., Hahne, A., 1993. Event-related brain potentials during natural speech processing: effects of semantic, morphological and syntactic violations. Brain Res. Cogn. Brain Res. 1, 183-192.

Friederici, A.D., von Cramon, D.Y., Kotz, S.A., 1999. Language related brain potentials in patients with cortical and subcortical left hemisphere lesions. Brain 122, 1033-1047.

Friederici, A.D., Wang, Y.H., Herrmann, C.S., Maess, B., Oertel, U., 2000. Localization of early syntactic processes in frontal and temporal cortical areas: a magnetoencephalographic study. Hum. Brain Mapp. 11, 1-11.

Friederici, A.D., Rüschemeyer, S.A., Hahne, A., Fiebach, C.J., 2003. The role of left inferior frontal and superior temporal cortex in sentence comprehension: localizing syntactic and semantic processes. Cereb. Cortex 13, 170-177.

Friederici, A.D., Kotz, S.A., Scott, S.K., Obleser, J., 2010. Disentangling syntax and intelligibility in auditory language comprehension. Hum. Brain Mapp. 31, 448-457.

Friston, K., 2002. Beyond phrenology: what can neuroimaging tell us about distributed circuitry? Annu. Rev. Neurosci. 25, 221-250.

Friston, K., 2010. The free-energy principle: a unified brain theory? Nat. Rev. Neurosci. 11, 127-138.

Frost, M.A., Goebel, R., 2012. Measuring structural-functional correspondence: spatial variability of specialised brain regions after macro-anatomical alignment. Neurolmage 59, 1369-1381.

Fuchs, M., Wagner, M., Kohler, T., Wischmann, H.A., 1999. Linear and nonlinear current density reconstructions. J. Clin. Neurophysiol. 16, 267-295.
Fuchs, M., Wagner, M., Kastner, J., 2007. Development of volume conductor and source models to localize epileptic foci. J. Clin. Neurophysiol. 24, 101-119.

Gaab, N., Gaser, C., Zaehle, T., Jäncke, L., Schlaug, G., 2003. Functional anatomy of pitch memory - an fMRI study with sparse temporal sampling. Neurolmage 19, 1417-1426.

Gaillard, R., et al., 2006. Direct intracranial, fMRI, and lesion evidence for the causal role of left inferotemporal cortex in reading. Neuron 50, 191-204.

Garza Villarreal, E.A., Brattico, E., Leino, S., Ostergaard, L., Vuust, P., 2011. Distinct neural responses to chord violations: a multiple source analysis study. Brain Res. 1389, 103-114.

Gelfand, J.R., Bookheimer, S.Y., 2003. Dissociating neural mechanisms of temporal sequencing and processing phonemes. Neuron 38, 831-842.

Grodzinsky, Y., Santi, A., 2008. The battle for Broca's region. Trends Cogn. Sci. 12, 474-480.

Groß, J., Ioannides, A.A., Dammers, J., Maess, B., Friederici, A.D., Müller-Gärtner, H.W., 1998. Magnetic field tomography analysis of continuous speech. Brain Topogr. $10,273-281$.

Hagoort, P., 2005. On Broca, brain, and binding: a new framework. Trends Cogn. Sci. 9, $416-423$

Hagoort, P., 2009. Reflections on the neurobiology of syntax. In: Bickerton, D., Szathmáry, E. (Eds.), Biological Foundations and Origin of Syntax. MIT Press, Cambridge, MA, pp. 279-296.

Hahne, A., Friederici, A.D., 1999. Electrophysiological evidence for two steps in syntactic analysis. Early automatic and late controlled processes. J. Cogn. Neurosci. 11, 194-205.

Hämäläinen, M.S., Ilmoniemi, R.J., 1994. Interpreting magnetic fields of the brain: minimum norm estimates. Med. Biol. Eng. Comput. 32, 35-42.

Henson, R.N., Burgess, N., Frith, C.D., 2000. Recoding, storage, rehearsal and grouping in verbal short-term memory: an fMRI study. Neuropsychologia 38, 426-440.

Herrmann, B., Maess, B., Hasting, A.S., Friederici, A.D., 2009. Localization of the syntactic mismatch negativity in the temporal cortex: an MEG study. Neurolmage 48, 590-600.

Herrmann, B., Maess, B., Friederici, A.D., 2011a. Violation of syntax and prosody disentangling their contributions to the early left anterior negativity (ELAN). Neurosci. Lett. 490, 116-120.

Herrmann, B., Maess, B., Hahne, A., Schroger, E., Friederici, A.D., 2011b. Syntactic and auditory spatial processing in the human temporal cortex: an MEG study. NeuroImage 57, 624-633.

Hickok, G., Buchsbaum, B., Humphries, C., Muftuler, T., 2003. Auditory-motor interaction revealed by fMRI: speech, music, and working memory in area Spt. J. Cogn. Neurosci. 15, 673-682.

Humphries, C., Love, T., Swinney, D., Hickok, G., 2005. Response of anterior temporal cortex to syntactic and prosodic manipulations during sentence processing. Hum. Brain Mapp. 26, 128-138.

Humphries, C., Binder, J.R., Medler, D.A., Liebenthal, E., 2006. Syntactic and semantic modulation of neural activity during auditory sentence comprehension. J. Cogn. Neurosci. 18, 665-679.

Ilmoniemi, R.J., 1991. Estimates of neuronal current distributions. Acta Otolaryngol. 80-87.

Indefrey, P., Levelt, W.J.M., 2004. The spatial and temporal signatures of word production components. Cognition 92, 101-144.

Jentschke, S., Koelsch, S., 2009. Musical training modulates the development of syntax processing in children. Neurolmage 47, 735-744.

Jentschke, S., Koelsch, S., Friederici, A.D., 2005. Investigating the relationship of music and language in children: influences of musical training and language impairment. Ann. N. Y. Acad. Sci. 1060, 231-242.

Jentschke, S., Koelsch, S., Sallat, S., Friederici, A.D., 2008. Children with specific language impairment also show impairment of music-syntactic processing. J. Cogn. Neurosci. 20, 1940-1951.

Kaan, E., Swaab, T.Y., 2002. The brain circuitry of syntactic comprehension. Trends Cogn. Sci. 6, 350-356.

Katz, J., Pesetsky, D., 2011. The Identity Thesis of Language and Music. lingBuzz/000959.

Kim, S.G., Kim, J.S., Chung, C.K., 2011. The effect of conditional probability of chord progression on brain response: an MEG study. PLoS One 6, e17337.

Klein, M.E., Zatorre, R.J., 2011. A role for the right superior temporal sulcus in categorical perception of musical chords. Neuropsychologia 49 (5), 878-887.

Knösche, T.R., Praamstra, P., Stegeman, D., Peters, M., 1996. Linear estimation discriminates midline sources and a motor cortex contribution to the readiness potential. Electroencephalogr. Clin. Neurophysiol. 99, 183-190.

Knösche, T.R., Maess, B., Friederici, A.D., 1999. Processing of syntactic information monitored by brain surface current density mapping based on MEG. Brain Topogr. 12, $75-87$.

Koelsch, S., 2005. Neural substrates of processing syntax and semantics in music. Curr. Opin. Neurobiol. 15, 207-212.

Koelsch, S., 2009. Music-syntactic processing and auditory memory: similarities and differences between ERAN and MMN. Psychophysiology 46, 179-190.

Koelsch, S., 2011. Toward a neural basis of music perception - a review and updated model. Front. Psychol. 2, 1-20.

Koelsch, S., 2012. Brain and Music. Wiley-Blackwell, Chichester.

Koelsch, S., Gunter, T., Friederici, A.D., Schröger, E., 2000. Brain indices of music processing: "nonmusicians" are musical. J. Cogn. Neurosci. 12, 520-541.

Koelsch, S., Maess, B., Gunter, T.C., Friederici, A.D., 2001. Neapolitan chords activate the area of Broca. A magnetoencephalographic study. Ann. N. Y. Acad. Sci. 930, 420-421.

Koelsch, S., Gunter, T.C., von Cramon, D.Y., Zysset, S., Lohmann, G., Friederici, A.D., 2002. Bach speaks: a cortical "language-network" serves the processing of music. Neurolmage 17, 956-966. 
Koelsch, S., Gunter, T.C., Wittfoth, M., Sammler, D., 2005a. Interaction between syntax processing in language and in music: an ERP Study. J. Cogn. Neurosci. 17, 1565-1577.

Koelsch, S., Fritz, T., Schulze, K., Alsop, D., Schlaug, G., 2005b. Adults and children processing music: an fMRI study. NeuroImage 25, 1068-1076.

Koelsch, S., Jentschke, S., Sammler, D., Mietchen, D., 2007. Untangling syntactic and sensory processing: an ERP study of music perception. Psychophysiology 44, 476-490.

Koelsch, S., Schulze, K., Sammler, D., Fritz, T., Müller, K., Gruber, O., 2009. Functional architecture of verbal and tonal working memory: an fMRI study. Hum. Brain Mapp. 30, 859-873.

Korzyukov, O., Pflieger, M.E., Wagner, M., Bowyer, S.M., Rosburg, T., Sundaresan, K., Elger, C.E., Boutros, N.N., 2007. Generators of the intracranial P50 response in auditory sensory gating. Neurolmage $35,814-826$.

Kovalev, D., Spreer, J., Honegger, J., Zentner, J., Schulze-Bonhage, A., Huppertz, H.J., 2005. Rapid and fully automated visualization of subdural electrodes in the presurgical evaluation of epilepsy patients. AJNR Am. J. Neuroradiol. 26, 1078-1083.

Krumhansl, C., 2004. The cognition of tonality - as we know it today. J. N. Music Res. 33, 253-268

Lachaux, J.P., Rudrauf, D., Kahane, P., 2003. Intracranial EEG and human brain mapping. J. Physiol. Paris 97, 613-628.

Lau, E., Stroud, C., Plesch, S., Phillips, C., 2006. The role of structural prediction in rapid syntactic analysis. Brain Lang. 98, 74-88.

Lerdahl, F., Jackendoff, R., 1983. A Generative Theory of Tonal Music. MIT Press, Cambridge.

Lesser, R.P., Crone, N.E., Webber, W.R.S., 2010. Subdural electrodes. Clin. Neurophysiol. $121,1376-1392$

Levitin, D.J., Menon, V., 2003. Musical structure is processed in "language" areas of the brain: a possible role for Brodmann Area 47 in temporal coherence. Neurolmage 20, 2142-2152.

Maess, B., Koelsch, S., Gunter, T.C., Friederici, A.D., 2001. Musical syntax is processed in Broca's area: an MEG study. Nat. Neurosci. 4, 540-545.

Maidhof, C., Koelsch, S., 2011. Effects of selective attention on syntax processing in music and language. J. Cogn. Neurosci. 23, 2252-2267.

Marin, M.M., 2009. Effects of early musical training on musical and linguistic syntactic abilities. Ann. N. Y. Acad. Sci. 1169, 187-190.

Mazziotta, J.C., Toga, A.W., Evans, A., Fox, P., Lancaster, J., 1995. A probabilistic atlas of the human brain - theory and rationale for its development. Neurolmage 2, 89-101.

Menon, V., Freeman, W.J., Cutillo, B.A., Desmond, J.E., Ward, M.F., Bressler, S.L., Laxer, K.D., Barbaro, N., Gevins, A.S., 1996. Spatio-temporal correlations in human gamma band electrocorticograms. Electroencephalogr. Clin. Neurophysiol. 98, 89-102.

Michel, C.M., Murray, M.M., Lantz, G., Gonzalez, S., Spinelli, L., Grave de Peralta, R., 2004. EEG source imaging. Clin. Neurophysiol. 115, 2195-2222.

Minati, L., Rosazza, C., D'Incerti, L., Pietrocini, E., Valentini, L., Scaioli, V., Loveday, C., Bruzzone, M.G., 2008. FMRI/ERP of musical syntax: comparison of melodies and unstructured note sequences. Neuroreport 19,1381-1385.

Moro, A., Tettamanti, M., Perani, D., Donati, C., Cappa, S.F., Fazio, F., 2001. Syntax and the brain: disentangling grammar by selective anomalies. Neurolmage 13, 110-118.

Musso, M., Moro, A., Glauche, V., Rijntjes, M., Reichenbach, J., Büchel, C., Weiller, C., 2003. Broca's area and the language instinct. Nat. Neurosci. 6, 774-781.

Neville, H., Nicol, J.L., Barss, A., Forster, K.I., Garrett, M.F., 1991. Syntactically based sentence processing classes - evidence from event-related brain potentials. J. Cogn. Neurosci. 3, 151-165.

Noppeney, U., Price, C.J., 2004. An fMRI study of syntactic adaptation. J. Cogn. Neurosci. $16,702-713$.

Nowagk, R., Pfeifer, E., 1996. Unix implementation of the ERP evaluation package (EEP 3.0). In: Friederici, A.D., von Cramon, D.Y. (Eds.), Annual Report. Max Planck Institute for Cognitive Neuroscience, Leipzig, pp. 124-126.

Ojemann, G.A., 1979. Individual variability in cortical localization of language. J. Neurosurg. 50, 164-169.

Oldfield, R.C., 1971. The assessment and analysis of handedness: the Edinburgh inventory. Neuropsychologia 9, 97-113.

Patel, A.D., 2003. Language, music, syntax and the brain. Nat. Neurosci. 6, 674-681.

Patel, A.D., 2008. Music, Language, and the Brain. Oxford University Press, New York.

Patel, A.D., Iversen, J.R., Wassenaar, M., Hagoort, P., 2008. Musical syntax processing in agrammatic Broca's aphasia. Aphasiology 22, 776-789.

Paulesu, E., Frith, C.D., Frackowiak, R.S., 1993. The neural correlates of the verbal component of working memory. Nature 362, 342-345.

Piston, W., 1948/1987. Harmony. Norton, New York.

Platel, H., Price, C., Baron, J.C., Wise, R., Lambert, J., Frackowiak, R.S.J., Lechevalier, B. Eustache, F., 1997. The structural components of music perception - a functional anatomical study. Brain 120, 229-243.

Price, C., 2010. The anatomy of language: a review of 100 fMRI studies published in 2009. Ann. N. Y. Acad. Sci. 1191, 62-88.

Pulvermüller, F., 2002. A brain perspective on language mechanisms: from discrete neuronal ensembles to serial order. Prog. Neurobiol. 67, 85-111.

Pulvermüller, F., Shtyrov, Y., 2006. Language outside the focus of attention: the mismatch negativity as a tool for studying higher cognitive processes. Prog. Neurobiol. 79, 49-71.

Pulvermüller, F., Shtyrov, Y., Hasting, A.S., Carlyon, R.P., 2008. Syntax as a reflex: neurophysiological evidence for early automaticity of grammatical processing. Brain Lang. 104, 244-253.

Ravizza, S.M., Delgado, M.R., Chein, J.M., Becker, J.T., Fiez, J.A., 2004. Functional dissociations within the inferior parietal cortex in verbal working memory. Neurolmage 22, 562-573.

Rogalsky, C., Rong, F., Saberi, K., Hickok, G., 2011. Functional anatomy of language and music perception: temporal and structural factors investigated using functional magnetic resonance imaging. J. Neurosci. 31, 3843-3852.
Rohrmeier, M., 2011. Towards a generative syntax of tonal harmony. J. Math. Music $5,35-53$

Rousseau, J.-J., 1781/1998. Essay on the Origin of Languages and Writings Related to Music. University Press of New England, Hanover, $\mathrm{NH}$

Rüschemeyer, S.A., Fiebach, C.J., Kempe, V., Friederici, A.D., 2005. Processing lexical semantic and syntactic information in first and second language: fMRI evidence from German and Russian. Hum. Brain Mapp. 25, 266-286.

Sahin, N.T., Pinker, S., Cash, S.S., Schomer, D., Halgren, E., 2009. Sequential processing of lexical, grammatical, and phonological information within Broca's area. Science $326,445-449$

Sammler, D., 2009. The Neuroanatomical Overlap of Syntax Processing in Music and Language - Evidence from Lesion and Intracranial ERP studies. Max Planck Institute for Human Cognitive and Brain Sciences, Leipzig.

Sammler, D., Koelsch, S., Friederici, A.D., 2011. Are left fronto-temporal brain areas a prerequisite for normal music-syntactic processing? Cortex 47, 659-673.

Schmithorst, V.J., 2005. Separate cortical networks involved in music perception: preliminary functional MRI evidence for modularity of music processing. Neurolmage 25, 444-451.

Schönberg, A., 1969. Structural Function of Harmony. Norton, New York.

Schulze, K., Zysset, S., Mueller, K., Friederici, A.D., Koelsch, S., 2011. Neuroarchitecture of verbal and tonal working memory in nonmusicians and musicians. Hum. Brain Mapp. 32 (5), 771-783.

Shalom, D.B., Poeppel, D., 2008. Functional anatomic models of language: assembling the pieces. Neuroscientist 14, 119-127.

Slevc, L.R., Rosenberg, J.C., Patel, A.D., 2009. Making psycholinguistics musical: selfpaced reading time evidence for shared processing of linguistic and musical syntax. Psychon. Bull. Rev. 16, 374-381.

Snijders, T.M., Vosse, T., Kempen, G., Van Berkum, J.J., Petersson, K.M., Hagoort, P., 2009 Retrieval and unification of syntactic structure in sentence comprehension: an fMRI study using word-category ambiguity. Cereb. Cortex 19, 1493-1503.

Spitsyna, G., Warren, J.E., Scott, S.K., Turkheimer, F.E., Wise, R.J.S., 2006. Converging language streams in the human temporal lobe. J. Neurosci. 26, 7328-7336.

Steinbeis, N., Koelsch, S., 2008. Shared neural resources between music and language indicate semantic processing of musical tension-resolution patterns. Cereb. Cortex $18,1169-1178$.

Steinhauer, K., Drury, J.E., 2012. On the early left-anterior negativity (ELAN) in syntax studies. Brain Lang. 120, 135-162.

Tervaniemi, M., Kujala, A., Alho, K., Virtanen, J., Ilmoniemi, R.J., Näätänen, R., 1999. Functional specialization of the human auditory cortex in processing phonetic and musical sounds: a Magnetoencephalographic (MEG) study. NeuroImage 9, 330-336.

Tettamanti, M., Weniger, D., 2006. Broca's area: a supramodal hierarchical processor? Cortex 42, 491-494.

Tillmann, B., Janata, P., Bharucha, J.J., 2003. Activation of the inferior frontal cortex in musical priming. Cogn. Brain Res. 16, 145-161.

Tillmann, B., Koelsch, S., Escoffier, N., Bigand, E., Lalitte, P., Friederici, A.D., von Cramon, D.Y., 2006. Cognitive priming in sung and instrumental music: activation of inferior frontal cortex. NeuroImage 31, 1771-1782.

Tyler, L.K., Marslen-Wilson, W., 2008. Fronto-temporal brain systems supporting spoken language comprehension. Phil. Trans. R. Soc. Lond B Biol. Sci. 363, 1037-1054.

Tyler, L.K., Marslen-Wilson, W.D., Randall, B., Wright, P., Devereux, B.J., Zhuang, J. Papoutsi, M., Stamatakis, E.A., 2011. Left inferior frontal cortex and syntax: function, structure and behaviour in patients with left hemisphere damage. Brain $134,415-431$

Ullman, M.T., 2001. A neurocognitive perspective on language: the declarative/procedural model. Nat. Rev. Neurosci. 2, 717-726.

Vandenberghe, R., Nobre, A.C., Price, C.J., 2002. The response of left temporal cortex to sentences. J. Cogn. Neurosci. 14, 550-560.

Vigneau, M., Beaucousin, V., Herve, P.Y., Duffau, H., Crivello, F., Houde, O., Mazoyer, B., Tzourio-Mazoyer, N., 2006. Meta-analyzing left hemisphere language areas: phonology, semantics, and sentence processing. Neurolmage 30, 1414-1432.

Vigneau, M., Beaucousin, V., Herve, P.Y., Jobard, G., Petit, L., Crivello, F., Mellet, E., Zago, L., Mazoyer, B., Tzourio-Mazoyer, N., 2011. What is right-hemisphere contribution to phonological, lexico-semantic, and sentence processing? Insights from a metaanalysis. NeuroImage 54, 577-593.

Vines, B.W., Schnider, N.M., Schlaug, G., 2006. Testing for causality with transcranial direct current stimulation: pitch memory and the left supramarginal gyrus. Neuroreport 17 , 1047-1050.

Vuust, P., Ostergaard, L., Pallesen, K.J., Bailey, C., Roepstorff, A., 2009. Predictive coding of music - brain responses to rhythmic incongruity. Cortex 45, 80-92.

Wallin, N.L., Merker, B., Brown, S. (Eds.), 2000. The Origins of Music. MIT Press, Cambridge.

Zanow, F., Knösche, T.R., 2004. ASA - Advanced Source Analysis of continuous and event-related EEG/MEG signals. Brain Topogr. 16, 287-290.

Zatorre, R.J., Evans, A.C., Meyer, E., 1994. Neural mechanisms underlying melodic perception and memory for pitch. J. Neurosci. 14, 1908-1919.

Zatorre, R.J., Belin, P., Penhune, V.B., 2002. Structure and function of auditory cortex: music and speech. Trends Cogn. Sci. 6, 37-46.

Zaveri, H.P., Duckrow, R.B., Spencer, S.S., 2009. Concerning the observation of an electrical potential at a distance from an intracranial electrode contact. Clin. Neurophysiol. 120, 1873-1875.

Zhang, Y., van Drongelen, W., Kohrman, M., He, B., 2008. Three-dimensional brain current source reconstruction from intra-cranial ECoG recordings. NeuroImage 42, 683-695. 